\title{
KẾT QUẢ ĐIỀU TRỊ U TUYẾN LỆ
}

\section{Hà Thị Thu Hà', Nguyễn Thị Thanh Hương', Nguyễn Quốc Anh', Phạm Trọng Văn ${ }^{2}$}

\section{TÓM TẮT}

U tuyến lệ là một bệnh có đặc điểm tổn thương đa hình thái đòi hỏi các phương pháp điều trị khác nhau. Mục tiêu nghiên cứu nhằm đánh giá kết quả điều trị u tuyến lệ (bao gồm u biểu mô tuyến lệ và u lympho tuyến lệ). Phương pháp nghiên cứu mô tả tiến cứu trên 108 bệnh nhân đến khám và điều trị u tuyến lệ tai Bênh viện Mắt Trung ương từ tháng 10 năm 2016 đến tháng 12 năm 2019 có kết quả giải phẫu bệnh xác đinh. Kết quả: Trong 108 ca u tuyển lê có 33 ca u biểu mô tuyến lệ (17 ca u hô̂n hợp tuyến lệ (HHTL) lành tính và 16 ca ung thư biểu mồ (UTBM) tuyến lệ) và 75 ca u lympho tuyến lệ (47 ca quá sản lympho và 28 ca lymphoma). Các phương pháp điêuu trị u tuyến lệ bao gồm phẫu thuật $(28,21 \%)$, hóa trị $(20,51 \%)$, xa tri $(9,4 \%)$, corticoid $(41,03 \%)$, miễn dịch $(0,85 \%)$. Kết luận: Điều trị u tuyến lệ phụ thuộc vào loại u tuyến lệ và có nhiêu phương pháp khác nhau, có thể điều trị một hoặc phối hợp nhiều phương pháp.

Tư khóa: Ủ tuyến lệ, u hốn hợp tuyến lệ, ung thư biểu mô dạng tuyến nang tuyến lệ, quá sản lympho, lymphoma, điêu trị u tuyến lệ.

\section{SUMMARY \\ TREATMENT OF LACRIMAL GLAND TUMOURS}

Lacrimal gland tumours comprise a wide variety of lesions requiring different treatment strategies. Purposes was to evaluate treatment results of lacimal gland tumours (included epithelial tumours and lympho tumours). Subjects of methods: Descriptive research methodology in 108 patients with lacrimal gland tumours in VNIO from October 2016 to September 2019. Most of them have histology results. Results: Among 108 cases of lacimal gland tumours, there were 33 cases of epithelial lacrimal gland tumours (17 cases of benign mixed tumours and 16 cases of lacrimal gland carcinoma ) and 75 cases of lymphoid tumours (47 cases of reactive and typical lymphoid hyperplasia and 28 cases of malignant lymphoma). The treatment methods include surgery $(28.21 \%)$, chemotherapy $(20.51 \%)$, radiotherapy $(9.4 \%)$, corticosteroids $(41.03 \%)$, immunology (0, $85 \%)$. Conclusions: Treatment for lacimal gland tumours depends on the type of tumours and there are many different methods that can be treated with one or combination of methods.

Key words: Lacrimal gland tumours, mixed

\footnotetext{
${ }^{1}$ Bệnh viện Mắt Trung Uơng

2Trường Đại học Y Hà Nội

Chịu trách nhiệm chính: Hà Thị Thu Hà

Email: autumndim2003@gmail.com

Ngày nhận bài: 2.3.2021

Ngày phản biện khoa học: 27.4.2021

Ngày duyệt bài: 7.5.2021
}

benign tumours, adenoid cystic carcinoma, reactive and typical lymphoid hyperplasia, lymphoma, treatment of lacimal gland tumours.

\section{I. ĐĂT VẤN ĐỀ}

U tuyến lệ là một khối sưng ở tuyến lệ có thể gây đè đẩy nhãn cấu, hạn chế vận nhãn và song thị. U tuyến lệ là tổn thương đa hình thái có triệu chứng lâm sàng tương tự nhau nhưng kết quả giải phẫu bệnh khác nhau và cách xử lý khác nhau. Bệnh hiếm gặp nhưng nếu là u ác tính thì độ ác tính rất cao [1]. U tuyến lệ chiếm $5 \%$ đến $10 \%$ các khối choán chỗ hốc mắt, trong đó tổn thương biểu mô chiếm 20\%, còn lại $80 \%$ là tổn thương không biểu mô (u lympho, viêm và các tổn thương khác). Trong số u biểu mô, 55\% lành tính và $45 \%$ ác tính. Trong số các u biểu mô lành tính hay gặp nhất là u HHTL lành tính (chiếm khoảng 20\% u tuyến lệ) [2]. Chẩn đoán giải phẫu bệnh giúp định hướng điêu trị và tiên lượng bệnh. Xử trí u HHTL lành tính là phẫu thuật, đường mổ qua mở thành ngoài xương. Đây là đường dễ tiếp cận nhất và cho phép loại bỏ toàn bộ khối u cả vỏ. Trong số các u biểu mô ác tính, UTBM dạng tuyến nang hay gặp nhất, chiếm $66 \%$, sau đó là u HHTL ác tính, UTBM tuyến... Điêuu trị tại chỗ UTBM dạng tuyến nang vẫn luôn là một chủ đề còn nhiêu tranh cãi. Một số tác giả ủng hộ phẫu thuật bảo tôn nhãn cầu (eye - sparing) + xạ trị ngoài (RT) hoặc xạ trị proton. Một số tác giả ủng hộ nạo vét tổ chức hốc mắt và cho rằng nạo vét tổ chức hốc mắt có thể kiểm soát bệnh nếu phẫu thuật triệt để sớm, kết quả có thể kéo dài thời gian sông sót [3] ]. U lympho tuyến lệ (tăng sinh lympho tuyến lệ) bao gồm quá sản lympho lành tính (phản ứng), quá sản lympho không điển hình (trung gian) và lymphoma. Điều trị u lympho bao gồm các hướng như sau: theo dõi, steroids toàn thân, xạ trị tại chỗ hoặc hóa chất. Chúng tôi tiến hành để tài nghiên cứu "Kết quả điều trị u tuyến lệ" nhằm hai mục tiêu sau:

-Đánh giá kết quả điều trị u biểu mô tuyên lệ -Đánh giá kết quả điều trị u lympho tuyến lệ

\section{II. ĐỐI TƯỢNG VÀ PHƯƠNG PHÁP NGHIÊN CỨU}

1. Tiêu chuẩn lựa chọn. Bệnh nhân đến khám và điều trị u tuyến lệ tại Bệnh viện Mắt Trung ương từ tháng 10 năm 2016 đến tháng 12 năm 2019 có kết quả giải phẫu bệnh xác định 
2. Tiêu chuẩn loại trừ. Bênh nhân có kết quả giải phẫu bệnh khổng xác định

-Bệnh nhân không được làm giải phẫu bệnh

3. Phương pháp nghiên cứu

*Thiết kế nghiên cứu: Nghiên cứu quan sát mô tả tiến cứu

*Cõ̃ mẫu nghiên cứu

Áp dụng công thức tính cõ̃ mẫu:

$$
\mathbf{n}=\mathrm{Z}^{2}{ }_{1-\alpha / 2} \frac{\mathrm{p}(1-\mathrm{p})}{(\mathrm{d})^{2}}
$$

$\mathrm{n}$ : cõ̃ mẫu nghiên cứu

z: trị số giớZ̆hạn đủa độ tin cậy. Chọn độ tin cậy là $95 \% \rightarrow \quad-1,96$

p: tỉ lệ bị bệnh, $p=5 \%$ (U tuyến lệ chiếm khoảng $7-9 \%$ khối u hốc mắt) d: độ chính xác tuyệt đối $(9 \%$ - 21\%) = 13\%

Qua tính toán $n$ ít nhất là 64 bệnh nhân. Hiện tại chúng tôi thu thập được 108 bệnh nhân.

*Cách chọn mấu nghiên cứu: Bắt đầu từ tháng 10 năm 2016 tất cả các bệnh nhân u tuyến lệ đáp ứng đủ tiêu chuẩn nghiển cứu được chọn ngẫu nhiên, liên tục cho đến tháng 12 năm 2018, theo dõi và dừng lại ở thời điểm BN cuối cùng theo dõi tháng 12 năm 2019. Cách chọn mẫu là ngẫu nhiên liên tục các bệnh nhân u tuyến lệ đáp ứng đủ tiêu chuẩn lựa chọn.

*Xử lý số liệu: theo chương trình SPSS 16.0

*Đạo đức nghiên cứu: Bệnh nhân tự nguyện tham gia nghiên cứu. Số liệu trung thực, khách quan được xử lý chính xác, khoa học.

\section{KẾT QUẢ NGHIÊN CỨU}

1. Các phương pháp điều trị u tuyến lệ chung

Bảng 1. Các phương pháp điều trị u tưyến lệ chung

\begin{tabular}{|c|c|c|c|c|c|c|c|c|c|c|}
\hline \multirow{2}{*}{$\begin{array}{l}\text { Các phương } \\
\text { pháp điêu trị }\end{array}$} & \multicolumn{2}{|c|}{$\begin{array}{l}\text { U HHTL } \\
\text { lành tính }\end{array}$} & \multicolumn{2}{|c|}{$\begin{array}{c}\text { UTBM tuyến } \\
\text { lẹ̣ }\end{array}$} & \multicolumn{2}{|c|}{$\begin{array}{l}\text { Quá sản } \\
\text { lympho }\end{array}$} & \multicolumn{2}{|c|}{ Lymphoma } & \multicolumn{2}{|c|}{ Tổng } \\
\hline & $\mathbf{n}$ & $\%$ & $\mathbf{n}$ & $\%$ & $\mathrm{n}$ & $\%$ & n & $\%$ & $\mathrm{n}$ & $\%$ \\
\hline Phầu thuật & 17 & 100 & 14 & 50 & 2 & 4,1 & 0 & 0 & 33 & 28,2 \\
\hline Xạ trị & 0 & 0,0 & 8 & 28,6 & 0 & 0,0 & 3 & 13 & 11 & 9,4 \\
\hline Hóa trị & 0 & 0,0 & 5 & 17,8 & 0 & 0,0 & 19 & 82,6 & 24 & 20,5 \\
\hline Corticoid & 0 & 0,0 & 1 & 3,6 & 46 & 93,9 & 1 & 4,4 & 48 & 41,1 \\
\hline Miên dịch & 0 & 0,0 & 0 & 0,0 & 1 & 2 & 0 & 0,0 & 1 & 0,9 \\
\hline Tống & 17 & 100 & 28 & 100 & 49 & 100 & 23 & 100 & 117 & 100 \\
\hline
\end{tabular}

2. Kết quả điều trị u biếu mô tuyến lệ

2.1 Phân bố bệnh nhân có chỉ định phầu thuật

Bảng 2. Phân bố bệnh nhân u biểu mô có chỉ định phẫu thuật

\begin{tabular}{|c|c|c|c|c|c|c|}
\hline \multirow{2}{*}{} & \multicolumn{2}{|c|}{ U HHTL lành tính } & \multicolumn{2}{c|}{ UTBM tuyến lệ } & \multicolumn{2}{c|}{ Tổng } \\
\cline { 2 - 7 } & $\mathbf{n}$ & $\mathbf{\%}$ & $\mathbf{n}$ & $\mathbf{\%}$ & $\mathbf{n}$ & $\mathbf{2}$ \\
\hline Không phẫu thuật & 0 & 0,0 & 2 & 12,5 & $\mathbf{2}$ & $\mathbf{6 , 1}$ \\
\hline Phẩu thuật & 17 & 100,0 & 14 & 87,5 & $\mathbf{3 1}$ & $\mathbf{9 3 , 9}$ \\
\hline Tống & $\mathbf{1 7}$ & $\mathbf{1 0 0}$ & $\mathbf{1 6}$ & $\mathbf{1 0 0}$ & $\mathbf{3 3}$ & $\mathbf{1 0 0}$ \\
\hline
\end{tabular}

2.2 Phân bố măt phấu thuật

Bảng 3. Phân bố mắt phấu thuật

\begin{tabular}{|c|c|c|c|c|c|c|}
\hline \multirow{2}{*}{} & \multicolumn{2}{|c|}{ U HHTL lành tính } & \multicolumn{2}{c|}{ UTBM tuyến lệ } & \multicolumn{2}{c|}{ Tổng } \\
\cline { 2 - 7 } & $\mathbf{n}$ & $\mathbf{\%}$ & $\mathbf{n}$ & $\%$ & $\mathrm{n}$ & $\%$ \\
\hline Mắt phải & 10 & 58,8 & 6 & 42,9 & 16 & 51,6 \\
\hline Mắt trái & 7 & 41,2 & 8 & 57,1 & 15 & 48,4 \\
\hline Tống & $\mathbf{1 7}$ & $\mathbf{1 0 0 , 0}$ & $\mathbf{1 6}$ & $\mathbf{1 0 0 , 0}$ & $\mathbf{3 3}$ & $\mathbf{1 0 0 , 0}$ \\
\hline
\end{tabular}

2.3 Các phương pháp phầu thuật

Bảng 4. Các phương pháp phấu thuật

\begin{tabular}{|c|c|c|c|c|c|c|}
\hline \multirow{2}{*}{ Phương pháp phẫu thuật } & \multicolumn{2}{|c|}{ U HHTL lành tính } & \multicolumn{2}{|c|}{ UTBM tuyến lệ } & \multicolumn{2}{|c|}{ Tống } \\
\cline { 2 - 7 } & $\mathbf{n}$ & $\mathbf{\%}$ & $\mathbf{n}$ & $\mathbf{\%}$ & $\mathbf{n}$ & $\mathbf{\%}$ \\
\hline Cắt u cả khối bao gồm vỏ & 17 & 100,0 & 2 & 11,7 & 19 & 55,9 \\
\hline Cắt u một phần & 0 & 0,0 & 2 & 11,8 & 2 & 5,9 \\
\hline $\begin{array}{c}\text { Cắt bỏ khối u rộng rãi bảo tồn nhãn } \\
\text { cầu (Eye - sparing) }\end{array}$ & 0 & 0,0 & 7 & 41,3 & 7 & 20,6 \\
\hline Cắt bó xương hốc mắt & 0 & 0,0 & 3 & 17,6 & 3 & 8,8 \\
\hline Nạo vét tố chức hốc mắt & 0 & 0,0 & 3 & 17,6 & 3 & 8,8 \\
\hline Tống & $\mathbf{1 7}$ & $\mathbf{1 0 0}$ & $\mathbf{1 7}$ & $\mathbf{1 0 0}$ & $\mathbf{3 4}$ & $\mathbf{1 0 0}$ \\
\hline
\end{tabular}




\section{4 Đường phẫu thuật u biểu mô tuyến lê}

Bảng 5. Đường phẫu thuật u biểu mô tuyến lệ

\begin{tabular}{|c|c|c|c|c|c|c|}
\hline \multirow{2}{*}{ Đường mổ } & \multicolumn{2}{c|}{ U HHTL lành tính } & \multicolumn{2}{|c|}{ UTBM tuyến lệ } & \multicolumn{2}{|c|}{ Tống } \\
\cline { 2 - 7 } & $\mathbf{n}$ & $\mathbf{\%}$ & $\mathbf{n}$ & $\mathbf{\%}$ & $\mathbf{n}$ & $\mathbf{\%}$ \\
\hline Stallard-Wright & 0 & 0,0 & 0 & 0,0 & 0 & 0,0 \\
\hline Reese-Berke & 0 & 0,0 & 0 & 0,0 & 0 & 0,0 \\
\hline Đường qua nếp mí trên không mở xương & 4 & 23,5 & 4 & 28,6 & 8 & 25,8 \\
\hline Đường qua nếp mí trên có mở xương & 9 & 52,9 & 2 & 14,3 & 11 & 35,5 \\
\hline Đường dưới cung lông mày & 1 & 5,9 & 2 & 14,3 & 3 & 9,7 \\
\hline Đường kết mạc cùng đồ trên & 3 & 17,6 & 1 & 7,1 & 4 & 12,9 \\
\hline Đường khác & 0 & 0,0 & 5 & 35,7 & 5 & 16,1 \\
\hline Tống & $\mathbf{1 7}$ & $\mathbf{1 0 0}$ & $\mathbf{1 4}$ & $\mathbf{1 0 0}$ & $\mathbf{3 1}$ & $\mathbf{1 0 0}$ \\
\hline
\end{tabular}

2.5 Đánh giá diến biến trong phẫu thuật

Bảng 6. Đánh giá diễn biến trong phẫu thuật

\begin{tabular}{|c|c|c|c|c|c|c|c|}
\hline \multirow{2}{*}{\multicolumn{2}{|c|}{ Diễn biến }} & \multicolumn{2}{|c|}{ U HHTL lành tính } & \multicolumn{2}{|c|}{ UTBM tuyến lệ } & \multicolumn{2}{|c|}{ Tống } \\
\hline & & $\mathbf{n}$ & $\%$ & $\mathbf{n}$ & $\%$ & $\mathbf{n}$ & $\%$ \\
\hline \multirow{2}{*}{ Sẹo mổ cũ } & Không & 15 & 88,2 & 7 & 50,0 & 22 & 71,0 \\
\hline & Có & 2 & 11,8 & 7 & 50,0 & 9 & 29,0 \\
\hline \multirow{2}{*}{$\begin{array}{c}\text { Tình trang tiếp cận } \\
\text { khối u }\end{array}$} & Dề & 17 & 100,0 & 11 & 78,6 & 28 & 90,3 \\
\hline & Khó & 0 & 0,0 & 3 & 21,4 & 3 & 9,7 \\
\hline \multirow{2}{*}{ Tình trạng xơ dính } & Không & 17 & 100,0 & 1 & 7,1 & 18 & 58,1 \\
\hline & Có & 0 & 0,0 & 13 & 92,9 & 13 & 41,9 \\
\hline \multirow{2}{*}{$\begin{array}{c}\text { Tình trang lấy bỏ } \\
\text { khối u }\end{array}$} & Lấy hết u & 17 & 100,0 & 10 & 71,4 & 27 & 87,1 \\
\hline & Lây môt phần u & 0 & 0,0 & 4 & 28,6 & 4 & 12,9 \\
\hline
\end{tabular}

2.6 Đăc điếm khôii u trong phấu thuật

Bảng 7. Đặc điểm khôii u trong phấu thuật

\begin{tabular}{|c|c|c|c|c|c|c|c|}
\hline \multirow{2}{*}{\multicolumn{2}{|c|}{ Đặc điểm khối u }} & \multicolumn{2}{|c|}{ U HंHTL lành tính } & \multicolumn{2}{|c|}{ UTBM tuyến lệ } & \multicolumn{2}{|c|}{ Tống } \\
\hline & & $\mathbf{n}$ & $\%$ & $\mathbf{n}$ & $\%$ & $\mathbf{n}$ & $\%$ \\
\hline \multirow{3}{*}{ Kích thước } & $\leq 2 \mathrm{~cm}$ & 5 & 29,4 & 4 & 28,6 & 9 & 29,0 \\
\hline & $2,1-4 \mathrm{~cm}$ & 12 & 70,6 & 8 & 57,1 & 20 & 64,5 \\
\hline & $>4 \mathrm{~cm}$ & 0 & 0,0 & 2 & 14,3 & 2 & 6,5 \\
\hline \multirow{4}{*}{ Hình dạng } & Tròn & 5 & 29,4 & 1 & 7,7 & 6 & 19,4 \\
\hline & Bầu dục & 10 & 58,8 & 11 & 78,6 & 21 & 67,7 \\
\hline & Thuôn & 0 & 0,0 & 2 & 14,3 & 2 & 6,5 \\
\hline & Nhiều thùy & 2 & 11,8 & 0 & 0,0 & 2 & 6,5 \\
\hline \multirow{2}{*}{ Bề mặt } & Nhằn & 16 & 94,1 & 2 & 14,3 & 18 & 58,1 \\
\hline & Gồ ghề & 1 & 5,9 & 12 & 85,7 & 13 & 41,9 \\
\hline \multirow{2}{*}{ Bờ } & Không đều & 0 & 0,0 & 12 & 85,7 & 12 & 38,7 \\
\hline & Đều & 17 & 100,0 & 2 & 14,3 & 19 & 61,3 \\
\hline \multirow{3}{*}{ Mật độ } & Rắn & 16 & 94,1 & 14 & 100 & 30 & 96,8 \\
\hline & Mềm & 1 & 5,9 & 0 & 0,0 & 1 & 3,2 \\
\hline & Nang dịch & 0 & 0,0 & 0 & 0,0 & 0 & 0,0 \\
\hline \multirow{2}{*}{ Ranh giới } & Lan tóa & 0 & 0,0 & 13 & 92,9 & 13 & 41,9 \\
\hline & Khu trú & 17 & 100,0 & 1 & 7,1 & 18 & 58,1 \\
\hline \multirow{2}{*}{$\begin{array}{l}\text { Mức đô̂ di } \\
\text { động }\end{array}$} & Di động & 9 & 52,9 & 0 & 0,0 & 19 & 29,0 \\
\hline & Cố định & 8 & 47,1 & 14 & 100 & 22 & 71,0 \\
\hline \multirow{2}{*}{$\begin{array}{l}\text { Thay đối cấu } \\
\text { trúc xương }\end{array}$} & Không & 13 & 76,5 & 8 & 57,1 & 21 & 67,7 \\
\hline & Có & 4 & 23,5 & 6 & 42,9 & 10 & 32,3 \\
\hline \multirow{2}{*}{$\begin{array}{c}\text { Cấu trúc tuyến } \\
\text { lệ }\end{array}$} & Còn cấu trúc tuyến lệ & 5 & 29,4 & 0 & 0,0 & 5 & 16,7 \\
\hline & $\begin{array}{c}\text { Thay đổi cấu trúc } \\
\text { tuyến lệ }\end{array}$ & 12 & 70,6 & 13 & 100 & 25 & 83,3 \\
\hline \multirow{2}{*}{$\begin{array}{c}\text { Phần tuyến lệ } \\
\text { tổn thương }\end{array}$} & Phần mi & 5 & 29,4 & 1 & 7,7 & 6 & 20,0 \\
\hline & Phần hốc mắt & 12 & 70,6 & 12 & 92,3 & 24 & 80,0 \\
\hline
\end{tabular}

3. Kết quả điều trị u lympho tuyến lệ 


\subsection{Phân bố bệnh nhân có chỉ định phẫu thuật}

Bảng 8. Phân bố bệnh nhân u lympho có chỉ định phẫu thuật

\begin{tabular}{|c|c|c|c|c|c|c|}
\hline \multirow{2}{*}{ Phẫu thuật } & \multicolumn{2}{|c|}{ Quá sản lympho } & \multicolumn{2}{c|}{ Lymphoma } & \multicolumn{2}{c|}{ Tống } \\
\cline { 2 - 7 } & $\mathbf{n}$ & $\mathbf{\%}$ & $\mathbf{n}$ & $\%$ & $\mathbf{n}$ & $\mathbf{\%}$ \\
\hline Không phâu thuật & 45 & 95,7 & 28 & 100,0 & $\mathbf{7 3}$ & $\mathbf{9 7 , 3}$ \\
\hline Phâuu thuật & 2 & 4,3 & 0 & 0,0 & $\mathbf{2}$ & $\mathbf{2 , 7}$ \\
\hline
\end{tabular}

3.2 Phân bố các phương pháp điêuu trị nội khoa u lympho

Bảng 9. Phân bố các phương pháp điêuu trị nội khoa u lympho

\begin{tabular}{|c|c|c|c|c|c|c|c|}
\hline \multirow{2}{*}{} & \multicolumn{2}{|c|}{ Quá sản lympho } & \multicolumn{2}{c|}{ Lymphoma } & \multicolumn{2}{c|}{ Tống } \\
\cline { 3 - 8 } \multicolumn{2}{|c|}{} & $\mathbf{n}$ & $\mathbf{0}$ & $\mathbf{n}$ & $\%$ & $\mathbf{n}$ & $\mathbf{\%}$ \\
\hline \multirow{2}{*}{ Hóa trị } & Không & 46 & 100 & 4 & 17,4 & $\mathbf{5 0}$ & $\mathbf{7 2 , 5}$ \\
\cline { 2 - 8 } & Có & 0 & 0,0 & 19 & 82,6 & $\mathbf{1 9}$ & $\mathbf{2 7 , 5}$ \\
\hline \multirow{2}{*}{ Xạ trị } & Không & 46 & 100 & 20 & 87,0 & $\mathbf{6 6}$ & $\mathbf{9 5 , 7}$ \\
\cline { 2 - 8 } & Có & 0 & 0,0 & 3 & 13,0 & $\mathbf{3}$ & $\mathbf{4 , 3}$ \\
\hline \multirow{2}{*}{ Corticoid } & Không & 0 & 0,0 & 22 & 95,7 & $\mathbf{2 2}$ & $\mathbf{3 1 , 9}$ \\
\cline { 2 - 8 } & Có & 46 & 100 & 1 & 4,3 & $\mathbf{4 7}$ & $\mathbf{6 8 , 1}$ \\
\hline \multirow{2}{*}{ Miễn dịch } & Không & 45 & 97,8 & 23 & 100 & $\mathbf{6 8}$ & $\mathbf{9 8 , 5}$ \\
\cline { 2 - 8 } & Có & 1 & 2,2 & 0 & 0,0 & $\mathbf{1}$ & $\mathbf{1 , 5}$ \\
\hline
\end{tabular}

\section{BÀN LUẬN}

4.1 Bàn luận về các phương pháp điêu trị u tuyến lệ chung. Trong kết quả nghiên cứu của chúng tôi, các phương pháp điều trị u tuyến lệ bao gồm phẫu thuật $(28,2 \%)$, xạ trị $(9,4 \%)$, liệu pháp corticoid $(41,1 \%)$ và miễn dịch (0,9\%). Trong nhóm u HHTL lành tính, 100\% phẫu thuậat. Trong nhóm UTBM tuyến lệ phương pháp phấu thuật chiếm $50 \%$ có thể kết hợp hoặc không kết hợp với xa trị hoặc hóa trị. Nhóm quá sản lympho chủ yếu dùng liệu pháp corticoid điều trị và nhóm lymphoma chủ yếu dùng phương pháp hóa trị. Theo Perez, tất cả các $B N$ u HHTL lành tính đều được cắt bỏ cả khối hoàn toàn, có duy nhất $1 \mathrm{BN}$ nạo vét hốc mắt năm 1974. Không có u nào tái phát sau điều trị. Các BN chủ yếu được điều trị phẫu thuật cắt u rộng rãi + xạ trị $(4 / 12 \mathrm{ca})$, phẫu thuật + xạ trị + hóa trị $(3 / 12 \mathrm{ca})$. Các trường hợp khác chỉ cắt bỏ u rộng rãi đơn thuần $(1 / 12)$, xạ trị và hóa trị (1/12). Có $1 / 12$ ca chỉ điêu trị nâng cao thể trạng [4]. Theo S. Mehdi Ahmad, các phương pháp điều trị cho UTBM dạng tuyến nang bao gồm: phẫu thuật Eye - sparing (bảo tồn nhãn cầu và cắt bỏ rộng rãi khối u) + không xạ trị, phẫu thuật Eye - sparing + xạ trị, nạo vét tổ chức hốc mắt + không cắt bỏ xương hốc mắt + xạ trị, nạo vét tổ chức hốc mắt + không cắt bỏ xương + không xạ trị, nạo vét tổ chức hốc mắt + cắt bỏ xương + xạ trị [5]. Theo James $P$. Farmer, 5 BN lymphoma nguyên phát có 4 BN bị tại chố đáp ứng tốt với xạ trị tại chỗ, $1 \mathrm{BN}$ từ MALT chuyển thành DLBCL cần hóa trị. Thông thường, trong quá trình phẫu thuật ban đầu cần cắt bỏ hầu hết hoặc toàn bộ tổ chức u.
4.2 Bàn luận về kết quả điều trị u biểu mô tuyến lệ. Bàn luận phân bố $B N$ u biểu mô tuyến lệ có chỉ định phẫu thuật. Trong số $33 \mathrm{ca}$ u biểu mô tuyến lệ có $93,9 \%$ có chỉ định phẫu thuật. Trong $17 \mathrm{BN}$ nhóm u HHTL lành tính, 100\% BN được phẫu thuật cắt bỏ khối u. Trong 16 BN nhóm UTBM tuyến lệ có $87,5 \%$ BN được phẫu thuật cắt bỏ khối u. Kết quả này tương tự với kết quả nghiên cứu của các tác giả khác đa số u biểu mô tuyến lệ đều có chỉ định phẫu thuật, mục đích là để cắt bỏ toàn bộ khối u bao gồm cả vỏ hoặc cắt một phần khối u tối đa có thể để làm giải phẫu bệnh, định hướng điều trị tiếp theo.

4.2.1 Bàn luận về phân bố mắt phẫu thuật. Trong 31 ca được phẫu thuật có $51,6 \%$ mắt phải và $48,4 \%$ mắt trái, Trong nhóm $U$ HHTL lành tính ưu thế bị bệnh ở mắt phải, nhóm UTBM tuyến lệ ưu thế ở mắt trái.

4.2.2 Bàn luận về các phương pháp phẫu thuật. Phương pháp phẫu thuật chính trong u biểu mô tuyến lệ là cắt bỏ u cả khối bao gồm vỏ chiếm $55,9 \%$ sau đó đến phương pháp Eye-sparing chiếm 20,6\%. Nhóm u HHTL lành tính $100 \%$ được cắt bỏ cả khối bao gồm cả vỏ. Nhóm UTBM tuyến lệ chủ yếu là cắt bỏ khối u rộng rãi và bảo tồn nhãn cầu (Eye-sparing). Ngoài ra còn có nạo vét tổ chức hốc mắt, cắt một phần khối $u$, các phương pháp này có thể phối hợp hoặc không phối hợp với cắt bỏ xương hốc mắt. Trong nghiên cứu của Pedro Claros trên 52 BN u HHTL lành tính, phẫu thuật cắt bỏ u HHTL lành tính qua đường mở thành ngoài xương trên $49 \mathrm{ca}(94,2 \%)$ có hoặc không có cắt bỏ dây chằng mi góc ngoài. Có $3 \mathrm{ca}$ mổ nội soi 
lấy u qua đường thành ngoài. Tất cả các ca mổ đều cắt bỏ toàn bộ khối u bao gồm cả vỏ. Theo Hind M. Alkatan, u HHTL lành tính là loại u biểu mô lành tính hay gặp nhất, được chẩn đoán chính xác và can thiệp ít nguy cơ tái phát tại chỗ nhất. Nhận biết dấu hiệu cắt bỏ không hoàn toàn bằng cách phát hiện dấu hiệu bị võ vỏ bọc u, điều này gây ra nguy cơ tái phát cao []ㅡ. Do vậy cần theo đánh giá kĩ bệnh nhân đã phẫu thuật cắt u HHTL lành tính. Trong nhóm nghiên cứu của Hind M. Alkatan, các bệnh nhân đều được phẫu thuật cắt $u$ hoàn toàn và giải quyết được các vấn đề khó chịu trước mổ.

4.3 Bàn luận về đường phẫu thuật. Trong 31 ca u biểu mô tuyến lệ được phẩu thuật, đường phẫu thuật hay dùng nhất là đường qua nếp mí trên có mở xương $(35,5 \%)$ và đường nếp mí trên không mở xương $(25,8 \%)$. Nhóm $U$ HHTL có 17 ca chủ yếu dùng đường nếp mí trên có mở xương (52,9\%). Nhóm UTBM tuyến lệ 14 ca có đường tiếp cận khối u đa dạng hơn, có các đường tiếp cận khác ngoài các đường nêu trên (đường khác chiếm 35,7\%).

4.4 Bàn luận về đánh giá diễn biến trong phẫu thuật. Trong $31 \mathrm{ca}$ u biểu mô tuyến lệ, $71 \%$ không có sẹo mổ cũ. Trong 17 ca u HHTL lành tính $88,2 \%$ không có sẹo mổ cũ. Trong 14 ca UTBM tuyến lệ, tî lệ BN có sẹo mổ cũ và không có đều chiếm $50 \%$. Hầu hết u biểu mô tuyến lệ trong phẫu thuật đều dễ tiếp cận khối u $(90,3 \%)$ và lần lượt chiếm tỉ lệ $100 \%$ và $78,6 \%$ ở u HHTL lành tính và UTBM tuyến lệ. Trong phẫu thuật u HHTL lành tính, $100 \%$ ca không có tình trạng xơ dính, ngược lại ở UTBM tuyến lệ có $92,9 \%$ bị xơ dính khi bóc tách u. Tình trạng lấy hết khối u trong phẫu thuật $u$ biểu mô tuyến lệ chiếm $87,1 \%$, u HHTL lành tính lây hết $100 \%$ khối u, UTBM tuyến lệ lấy hết u ở 71,4\% ca.

4.5 Bàn luận về đặc điểm khối u trong phẫu thuật. Vể kích thước khối u, 33 ca u biểu mô tuyến lệ chủ yếu có kích thước u trong khoảng 2,1-4cm (64,5\%), tương tự u HHTL lành tính và UTBM tuyến lấn lượt là $70,6 \%$ và $57,1 \%$. Hình dạng u chủ yếu là hình bầu dục: u biểu mô tuyến lệ chiếm $67,7 \%$, u HHTL lành tính chiếm $58,8 \%$, UTBM tuyến lệ chiếm $78,6 \%$. Bề mặt u ở nhóm u HHTL lành tính chủ yếu là nhẵn chiếm 94,1\%, ở nhóm UTBM tuyến lệ chủ yếu gồ ghề chiếm $85,7 \%$. Bờ khối u nhóm u HHTL lành tính chủ yếu là đều chiếm $100 \%$, ở nhóm UTBM tuyến chủ yếu không đều chiếm $85,7 \%$. Cả 2 nhóm u HHTL lành tính và UTBM của u biểu mô tuyến lệ đều có mật độ u chủ yếu là rắn chiếm lần lượt $94,1 \%$ và $100 \%$. Ranh giới u chủ yếu khu trú ở nhóm u HHTL lành tính chiếm 100\%, lan tỏa ở nhóm UTBM chiếm 92,9\%. U biểu mô tuyến lệ chủ yếu là u cố định $(71 \%)$, tỉ lệ cố định ở nhóm u HHTL lành tính và UTBM lần lượt chiếm $52,9 \%$ và $100 \%$. U biểu mô tuyến lệ chủ yếu là không thay đổi cấu trúc xương. Cả hai nhóm trong u biểu mô tuyến lệ đều đa số thay đổi cấu trúc tuyến lệ, đặc biệt nhóm UTBM tuyễn lệ thay đổi $100 \%$ cấu trúc tuyến lệ. Phần tuyên lệ thay đổi cấu trúc chủ yếu là phẩn hốc mắt, u HHTL lành tính là $70,6 \%$, UTBM tuyến lệ là $92,3 \%$. Kết quả này tương tự với kết quả của các nghiên cứu khác.

\subsection{Bàn luận về kết quả điêu trị u lympho tuyến lệ̣}

4.6.1 Bàn luận về phân bố BN u lympho tuyến lệ có chỉ định phấu thuật. Trong 75 BN nhóm u lympho tuyến lệ, 97,3\% BN không có chỉ định phẫu thuật, chỉ có $2,7 \%$ phẫu thuật. Trong 47 BN nhóm quá sản lyxmpho tuyến lệ, 95,7\% BN không có chỉ định phẫu thuật, chỉ có $4,3 \% \mathrm{BN}$ được phẫu thuật. Trong 28 BN nhóm lymphoma, $100 \%$ BN không phẫu thuật. Theo Liesegang, lymphoma ác tính thấp có thời gian phát triển dài và thời gian sống sót dài. BN bị lymphoma tế bào nhỏ hệ thống có thể thoái lưu tạm thời và chuyển sang độ ác tính cao hoặc ổn định trong thời gian dài. Vì lymphoma hệ thống ác tính thấp có ĐĐLS của u lành tính, điều trị hiện tại thường không thành công trong việc kiếm soát tiến triển bệnh. BN bị ác tính cao phản ứng tốt với điêuu trị. Xạ trị tại chố cho BN bị bệnh tại chỗ. Corticoid hệ thống có tác dụng với giả u viêm nhưng không dùng trong tăng sinh lympho. Xạ trị kiểm soát tại chổ nhưng có biến chứng là đục thể thủy tinh, tổn thương vóng mạc và viêm giác mạc. Hóa chất toàn thân cho lymphoma hệ thống. Thường phẫu thuật không hiệu quả vì u lympho thâm nhiễm [7].

4.6.2 Bàn luận về phân bố các phương pháp điều trị nội khoa u lympho. Trong nhóm quá sản lympho, 100\% BN dùng liệu pháp corticoid, có 1 BN dùng biện pháp miển dịch, không có BN nào hóa trị hoặc xạ trị. Trong số 69 BN lymphoma được điều trị có $82,6 \%$ BN hóa trị, $13 \%$ BN xạ trị, 4,3\% BN dùng corticoid, không có $\mathrm{BN}$ nào điều trị miễn dịch. Theo nghiên cứu của Ennio Polito, trong 33 bệnh nhân có 22 tăng sản lympho lành tính và 11 tăng sản lympho không điển hình. Trong nhóm quá sản lympho lành tính, bệnh ở tuyến lệ chiếm $11 / 22 \mathrm{ca}$ $(50 \%)$, và quá sản lympho không điển hình chiếm $3 / 11$ ca (27\%). Như vậy tăng sản lympho ở vị trí tuyến lệ chiếm $14 / 33$ ca (42\%). Điều trị 
dùng steroids toàn thân (Prednisone, $80 \mathrm{mg} / \mathrm{ngày}$, giảm liều dân) hoặc xạ trị ngoài hốc mắt (2000 - 2900 cGy) [8].

\section{KẾT LUÂN}

Các phương pháp điêu trị u tuyến lệ bao gôm phẫu thuật, xạ trị, hóa trị, corticoid và miễn dịch. U HHTL cắt cả khối bao gồm vỏ, UTBM tuyến lệ cắt một phân khối u là giải phẫu bệnh sau đó hóa trị hoặc xạ trị, quá sản lympho điêu trị bằng corticoid, lymphoma đáp ứng điều trị tốt với hóa trị.

\section{TÀI LIẸU THAM KHẢO}

1. Von Holstein, S.L., et al., Epithelial tumours of the lacrimal gland: a clinical, histopathological, surgical and oncological survey. Acta Ophthalmologica, 2013. 91(3): p. 195-206.

2. Andreasen, S., et al., An update on tumors of the lacrimal gland. The Asia-Pacific Journal of Ophthalmology, 2017. 6(2): p. 159-172.

3. Wright, J., Factors affecting the survival of patients with lacrimal gland tumours. Canadian journal of ophthalmology. Journal canadien d'ophtalmologie, 1982. 17(1): p. 3-9.

4. Perez, D.E., et al., Epithelial lacrimal gland tumors: a clinicopathological study of 18 cases. Otolaryngology-Head and Neck Surgery, 2006. 134(2): p. 321-325.

5. Ahmad, S.M., et al., American Joint Committee on Cancer classification predicts outcome of patients with lacrimal gland adenoid cystic carcinoma. Ophthalmology, 2009. 116(6): p. 1210-1215.

6. Alkatan, H.M., et al., Epithelial lacrimal gland tumors: A comprehensive clinicopathologic review of 26 lesions with radiologic correlation. Saudi journal of ophthalmology, 2014. 28(1): p. 49-57.

7. Liesegang, T.J. Ocular adnexal lymphoproliferative lesions. in Mayo Clinic Proceedings. 1993. Elsevier.

8. Polito, E., P. Galieni, and A. Leccisotti, Clinical and radiological presentation of 95 orbital lymphoid tumors. Graefe's archive for clinical and experimental ophthalmology, 1996. 234(8): p. 504-509.

\title{
HIÊUU QUẢ CAN THIÊPP MỨC Đô̂ ĐộC LÂ̂P CHỨC NĂNG SINH HOATT HÀNG NGÀY SAU PHỤC HỒI CHỨC NĂNG TAII NHÀ CHO NGƯỜI BỆNH ĐộT QUỴ NÃO Ở' THÀNH PHỐ THÁI NGUYÊN
}

\author{
Nguyễn Hoa Ngần ${ }^{1}$, Hoàng Khải Lập ${ }^{1}$, Nguyễn Phương Sinh ${ }^{1}$, \\ Trần Văn Tuấn ${ }^{1}$, Trương Mạnh Hà ${ }^{2}$, Đào Trọng Quân ${ }^{1}$
}

\section{TÓM TẮT}

Mục tiêu: Đánh giá hiệu quả phục hồi chức năng tại nhà về mức độc lập chức năng sinh hoạt hàng ngày cho người bệnh sau đột quy não ở Thành phố Thái Nguyên. Phương pháp nghiên cứu: Một nghiên cứu can thiệp cộng đồng có đối chứng được thực hiện trên 162 người bệnh đột quy não. Kết quả: Sau can thiệp 6 tháng, ở nhóm can thiệp, tỷ lệ người bệnh có mức độ phụ thuộc hoàn toàn giảm có ý nghĩa thống kê từ 55,6\% xuống 33,3\%. Mức độ độc lập đã tăng từ $1,2 \%$ lên $8,6 \%$ so với trước can thiệp. Ớ thời điểm 1 năm sau can thiêpp, tỷ lệ người bênh có mức độ phụ thuộc hoàn toàn giảm có ý nghĩa thống kê xuống $17,3 \%$, mức độ độc lập tăng lên $34,6 \%$ (p < $0,001)$. Hiệu quả can thiệp phục hồi chức năng trong việc cải thiện mức độ độc lập ở thời điểm 6 tháng đạt $17,0 \%$, ở thời điểm 1 năm đạt 28,0\%. Kết luận: Bài tập phưc hồi chức năng tại nhà có hiệu quả trong việc cải thiện mức độ độc lập chức năng sinh hoạt hàng ngày của người bệnh sau đột quỵ não.

${ }^{1}$ Trường Đại học Y Dược Thái Nguyên

²Bệnh viện $A$ Thái Nguyên

Chịu trách nhiệm chính: Nguyễn Hoa Ngần

Email: ngancdyttn@gmail.com

Ngày nhận bài: 4.3.2021

Ngày phản biện khoa học: 26.4.2021

Ngày duyệt bài: 6.5.2021
Tư khóa: Phục hồi chức năng, độc lập chức năng, sau đột quy. não

\section{SUMMARY}

THE EFFECT OF INTERVENTION ON DAILY LIVING FUNCTIONAL INDEPENDENCE AFTER REHABILITATION FOR PATIENTS

WITH STROKE AT THAI NGUYEN CITY

Object: Evaluate effect of home rehabilitation exersice in functional independence for post stroke patients at Thai Nguyen city. Method: A controlled experimental study was conducted on 162 stroke patients. Results: In intervention group after 6 months, the percentage of patients with completed dependence decreased significantly from $55.6 \%$ to $33.3 \%$. The completed independence increased from $1.2 \%$ to $8.6 \%$, compared with the time before the intervention. At the time of 1 year after the intervention, the proportion of patients with complete dependence decreased significantly to $17.3 \%$, the degree of independence increased to $34.6 \%$ ( $p$ $<0.001)$. The effectiveness of rehabilitation interventions in improving functional independence at the time of 6 months is $17.0 \%$, at a time of 1 year is $28.0 \%$. Conclusion: Home rehabilitation exercises are effective in improving the functional independence of daily living of patients after stroke.

Keywords: rehabilitation, independence, after stroke. 